\title{
Mechanosensor Channels in Mammalian Somatosensory Neurons
}

\author{
Matthieu Raoux, Lise Rodat-Despoix, Nathalie Azorin, Aurélie Giamarchi, Jizhe Hao, François \\ Maingret, Marcel Crest, Bertrand Coste and Patrick Delmas*
}

Laboratoire de Neurophysiologie Cellulaire, Centre National de la Recherche Scientifique UMR 6150, Université de la Méditerranée, Marseille, France

E-mails: Matthieu Raoux: matthieu.raoux @etumel.univmed.fr; Lise Rodat-Despoix: lise.rodatdespoix@univmed.fr; Nathalie Azorin: nathalie.azorin@univmed.fr; Aurélie Giamarchi:

aurelie.giamarchi@univmed.fr; Jizhe Hao: jizhe.hao@etumel.univmed.fr; François Maingret: francois.maingret@univmed.fr; Marcel Crest: marcel.crest@univmed.fr; Bertrand Coste: bertrand.coste@univmed.fr; Patrick Delmas: patrick.delmas@univmed.fr

* Author to whom correspondence should be addressed. E-mail: patrick.delmas@ univmed.fr Received:10 August 2007 / Accepted: 31 August 2007 / Published: 3 September 2007

\begin{abstract}
Mechanoreceptive sensory neurons innervating the skin, skeletal muscles and viscera signal both innocuous and noxious information necessary for proprioception, touch and pain. These neurons are responsible for the transduction of mechanical stimuli into action potentials that propagate to the central nervous system. The ability of these cells to detect mechanical stimuli impinging on them relies on the presence of mechanosensitive channels that transduce the external mechanical forces into electrical and chemical signals. Although a great deal of information regarding the molecular and biophysical properties of mechanosensitive channels in prokaryotes has been accumulated over the past two decades, less is known about the mechanosensitive channels necessary for proprioception and the senses of touch and pain. This review summarizes the most pertinent data on mechanosensitive channels of mammalian somatosensory neurons, focusing on their properties, pharmacology and putative identity.
\end{abstract}

Keywords: Pain, Touch, Skin sensation, Mechanosensory transduction, Stretch, Osmotic shock, Mechanosensitive channels, TRP channels, ASIC, amiloride, DRG. 


\section{Introduction}

In mammals, sensations coming from the skin (i.e., exteroception), muscles and joints (i.e., proprioception) and viscera (i.e., visceral pain) are mediated by the somatosensory nervous system. Primary somatosensory neurons are able to transduce a variety of thermal and nociceptive stimuli into action potentials that propagate toward the central nervous system. Most of these sensory neurons are also responsive to some forms of mechanical stimuli, and as such function as mechanoreceptors. The mechanical stimulation of these mechanoreceptors generates a variety of sensations, such as touch, pressure, vibration, proprioception and pain.

Sensory ganglia contain both low threshold mechanoreceptors (LTMs), which respond to light touch, vibration or internally generated movements, and high threshold mechanoreceptors (HTMs or mechanonociceptors) that sense noxious levels of pressure. Classically, numerous specialized or encapsulated endings (e.g. Golgi tendon organs and neuromuscular spindles in skeletal muscles, Meissner, Pacinian, Merkel and Ruffini corpuscles in the skin) are LTMs that are sensitive to innocuous touch, pressure and vibration, whereas a subset of A $\delta$ - and C-polymodal nociceptors responds to intense mechanical stimuli, and therefore, subserves mechanical pain sensation [1]. Mechanonociceptors have a very different mechanical response pattern than LTMs; they are not especially sensitive to moving stimuli but are instead selectively responsive to static indentation.

Neural signals of the somatic mechanosensation involve the excitation of the mechanoreceptive sensory endings. It is thought that mechanical forces applied to the sensory endings directly open mechanosensitive (MS) ion channels that depolarize the terminal. However, because of the small size and inaccessibility of sensory nerve endings, advances in understanding mechanical transduction mechanisms have been difficult and depended on the development of in vitro models of transduction [2]. Recent work in several laboratories determined that sensory neurons express various types of MS cation channels with distinct biophysical properties and subcellular pattern of expression [3-7]. This review highlights some recent developments regarding properties of these excitatory MS currents and their putative molecular counterparts in mammalian somatosensory neurons.

\section{Probing mechanosensor channels}

Mechanical forces may activate MS channels via multiple mechanisms such as membrane bilayer mechanics, physical coupling to intracellular or extracellular tethers and sensitivity to second messengers generated by MS receptors/enzymes [8]. These models are not necessarily mutually exclusive and MS channels may be activated by different stimuli. Owing to these multiple mechanisms of activation, recorded channels may vary depending on the technique considered. Therefore, in this section, we focus on the strategies and methods that enable monitoring mechanotransduction currents.

Several types of mechanical stimuli have been used to investigate MS channels, including piezodriven pressure, patch membrane stretch, shear stress, osmotic challenges and amphipathic compounds (Fig. 1). All these strategies are based on membrane deformation (Fig. 1), yet each has the potential to recruit different populations of MS channels. For example, strategies that entail membrane stretch via the application of positive or negative pressures to a patch electrode revealed MS cation channels with 
persistent behavior [9]. On the contrary, studies using piezo-driven mechanical probe primarily revealed rapidly and slowly adapting cation currents $[2,3,7]$.

\subsection{Piezo-driven pressure}

Deformation of the plasma membrane of sensory neurons using a piezo-electrically driven firepolished glass probe shows the most obvious analogy with mechanical somatodetection. The probe is typically positioned close to the cell surface at an angle $\geq 45^{\circ}$ in order to prevent transversal forces that could dislodge the cell from the substrate. The same software is generally used to drive the probe toward the cell and to record MS currents, allowing to control crucial parameters such as voltage and the intensity, velocity and duration of the mechanical stimulus. This technique, first developed in J.D. Levine's group, was applied to both cell bodies and neurites of sensory neurons in vitro [2,5].

\subsection{Cell stretch}

Some MS channels are activated by stretching the membrane bilayer. The opening of stretchactivated channels can be mediated either by fibrous proteins of the cytoskeleton or by physical changes in the lipid bilayer $[10,11]$. Two methods are commonly used to test for stretch sensitivity, that is, surface elongation of a flexible silicone elastomer substrate where cells were seeded [12] and application of positive or negative pressures to a patch membrane through a patch pipette [8]. The latter feature allowed the first recordings of stretch-activated ion channel currents more than 20 years ago [13].

\subsection{Fluid shear stress}

This technique consists in changing the physical properties of the superfusion solution. Two parameters can be modified to cause shear stress, $i$ ) the perfusion flow and ii) the viscosity of the solution.

Some cells are indeed sensitive to fluid-flow changes such as dorsal root ganglion neurons [2,14] and some endothelial and epithelial ciliated cells, which respond to an apical fluid shear stress by an increase in intracellular $\mathrm{Ca}^{2+}$ [15-17]. Fluid shear stress can regulate the tissue morphogenesis, particularly the lumen diameter of kidney tubules and blood vessels $[18,19]$. The hypothesis that mechanical stimulation might be physiologically caused by changes in the mucus viscosity was proposed for quite a while [20]. Recent studies confirmed that increasing the perfusion solution viscosity with $2-20 \%$ dextran, a complex branched polysaccharide, activates $\mathrm{Ca}^{2+}$ entry in ciliated epithelia [21,22].

\subsection{Osmotic challenges}

The plasma membrane of mammalian cells is more permeable to water than solutes. When the intracellular and extracellular media contain the same amount of osmolytes, they may be qualified isotonic with respect to each other. However, if one of them is less-concentrated, it may be qualified hypoosmotic and the net movement of water induced in the direction of the hyperosmotic compartment is called osmosis. The consequence of osmosis is a change in the cell volume: hypotonic conditions 
induce cell-swelling, whilst hypertonicity causes cell-shrinkage. Thus, due to deformation of cell morphology and lipid bilayer tensions, osmotic variations are considered as a type of mechanical stimulation by many authors [23-26].

Changes in osmotic pressure may affect most of mammalian cells and particularly sensory neurons that express a large panel of osmoregulated channels. Metabolic disturbances, cellular acidosis and hypoxia can increase the intracellular osmotic concentration [27-30]. Marked changes in the extracellular tonicity are observed in dehydrated tissues, in oedema, in abscesses [31,32] and in aquadynia (a cutaneous reaction to water) [33,34]. In addition, injection of mildly hypertonic saline is widely used as an experimental model of muscle or joint pain [35].

A hypoosmotic challenge can be reproduced experimentally by adding water or a very lowconcentrated solution to the extracellular medium [36,37]. Another possibility is to reduce (or increase in the case of hypertonicity) the external concentration of the main salt (generally $\mathrm{NaCl}$ ) [35,38]. These methods have the disadvantage to alter the ionic strength and the electrochemical equilibrium. This can be avoided by keeping constant the ionic concentrations during the challenge and by adding (for hypertonicity) or omitting (for hypotonicity) the appropriated concentration of a neutral osmolyte such as D-mannitol or sucrose [39-42].

(3)

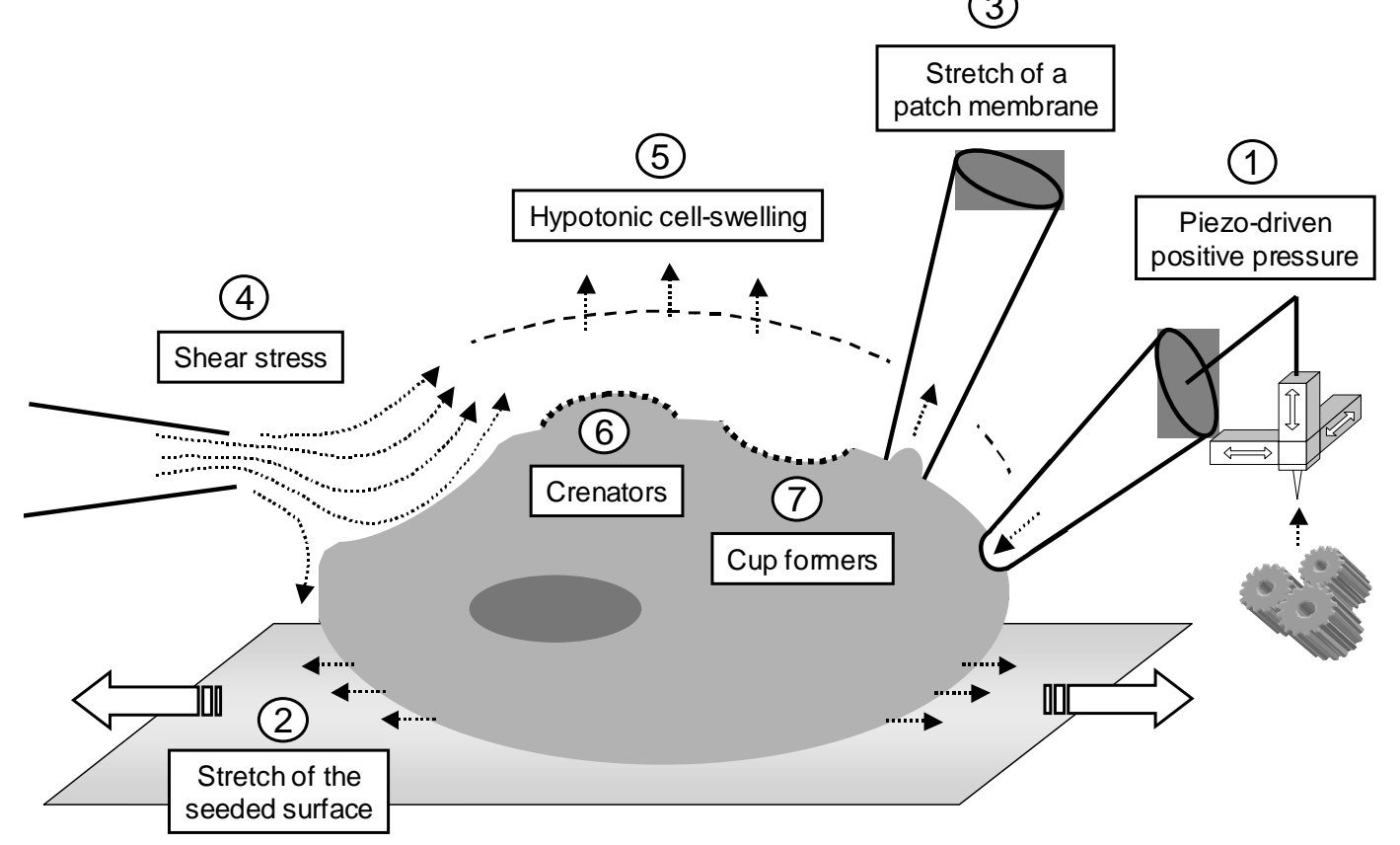

Figure 1. Diagrammatic representation of strategies used to cause cellular mechanoresponsiveness

A variety of mechanical stimuli can be applied to cells in vitro: (1) positive pressure using a piezo-electrically driven glass probe; (2) cell stretch caused by a flexible silicone elastomer; (3) stretch of the plasma membrane through a patch pipette; (4) fluid shear stress produced by changes in the flow or viscosity of the bathing solution; (5) cellswelling caused by hypotonic conditions; (6) convex deformation of the membrane caused by anionic or neutral amphipathic compounds and (7) concave deformation of the membrane caused by cationic amphipathic compounds. 


\subsection{Crenators and cup formers}

There is still a debate on how mechanical stimulus is transferred to the MS channel: is the activating force coming directly from the lipid bilayer or is the force transmitted through cytoskeleton elements? In order to answer this question one can modify the bilayer properties. Indeed, pioneer work using amphipathic molecules on erythrocytes demonstrated that the two halves of the membrane bilayer can act as bilayer couples [43]. Indeed, anionic and neutral amphipathic compounds such as free fatty acids, trinitrophenol and lysolecithin preferentially insert in the outer leaflet because of the natural asymmetric distribution of negatively charged phosphatidylserines in the inner leaflet. Consequently, these compounds induce the crenation of the erythrocyte plasma membrane. Conversely, positively charged amphipathic compounds such as chlorpromazine and tetracaine are expected to preferentially insert in the inner leaflet of the bilayer and cause the erythrocyte to form cup-shapes [43,44].

Such amphipathic molecules have been shown to activate the MS ion channel MscL from Escherichia coli with effectiveness proportional to their lipid solubility [45]. Moreover, the cationic or anionic amphipathic compounds were able to compensate for each other's effect. MS channels of the chick skeletal muscle are also directly activated either by such a convex or a concave deformation of the plasma membrane [46] and the activity of the recombinant mechano-gated two-pore-domain $\mathrm{K}^{+}$ channels TREK1 and TRAAK is enhanced by crenators while it is inhibited by cup formers $[47,48]$. Thus, the bilayer couple hypothesis assumes that the stretch activation derives entirely from interactions within the bilayer and is independent of the cytoskeleton.

\section{Biophysical properties of macroscopic MS currents in sensory neurons}

MS currents evoked in sensory neurons have a relatively short latency, which argues against activation of a second messenger cascade and favors direct activation of a mechanically-activated channel [5]. In response to sustained mechanical stimulation, MS currents decline or adapt, through closure of the transduction channels. Based on these adapting kinetics, 3 main classes of MS currents have been identified and loosely classified as either rapidly (RA), intermediately (IA) or slowly (SA) adapting (Fig. 2). A MS current that does not adapt within the testing range has been occasionally observed in sensory neurons [4,7]. This non-adapting MS current exhibits the particularity to peak during the stationary part of the mechanical stimulus (Fig. 2). Interestingly, these different MS currents are differentially distributed in subsets of sensory neurons. The majority of large diameter sensory neurons, which are mainly LTMs, express RA MS currents, whereas small and medium diameter sensory neurons preferentially display SA/non-adapting MS currents (Fig. 2) [3-5,7]. Differences in properties of MS currents among sensory neuron subpopulations in vitro are consistent with the in vivo physiological properties of LTMs and nociceptors [49].

RA and SA MS currents in sensory neurons exhibit reversal potentials at about $0 \mathrm{mV}$ and are carried by mechano-gated channels nonselective for cations and impermeable to anions $[4,6,7]$. The similarity in the ionic selectivity of these MS currents among different populations of sensory neurons suggests that closely related ion channel subunits mediate these currents. The ability of RA MS currents to pass large organic molecules such as TEA, choline and Tris strongly favors the view that the pore of the underlying MS channels is relatively large [6]. At variance, however, Hu and Lewin (2006) suggested 
that the RA MS current reversed at very positive potentials $(\sim+80 \mathrm{mV})$, suggestive of the participation of a pure $\mathrm{Na}^{+}$permeability [5].

While MS currents show the ability to be carried by $\mathrm{Ca}^{2+}$ and to a lesser extent by $\mathrm{Mg}^{2+}$, both $\mathrm{Ca}^{2+}$ and $\mathrm{Mg}^{2+}$ at physiological concentrations produce a partial block of MS currents [3,6]. Although the mechanism of block is still unknown, it may be due to a $\mathrm{Ca}^{2+}$ binding site within the pore causing reduced permeation to $\mathrm{Na}^{+}$.
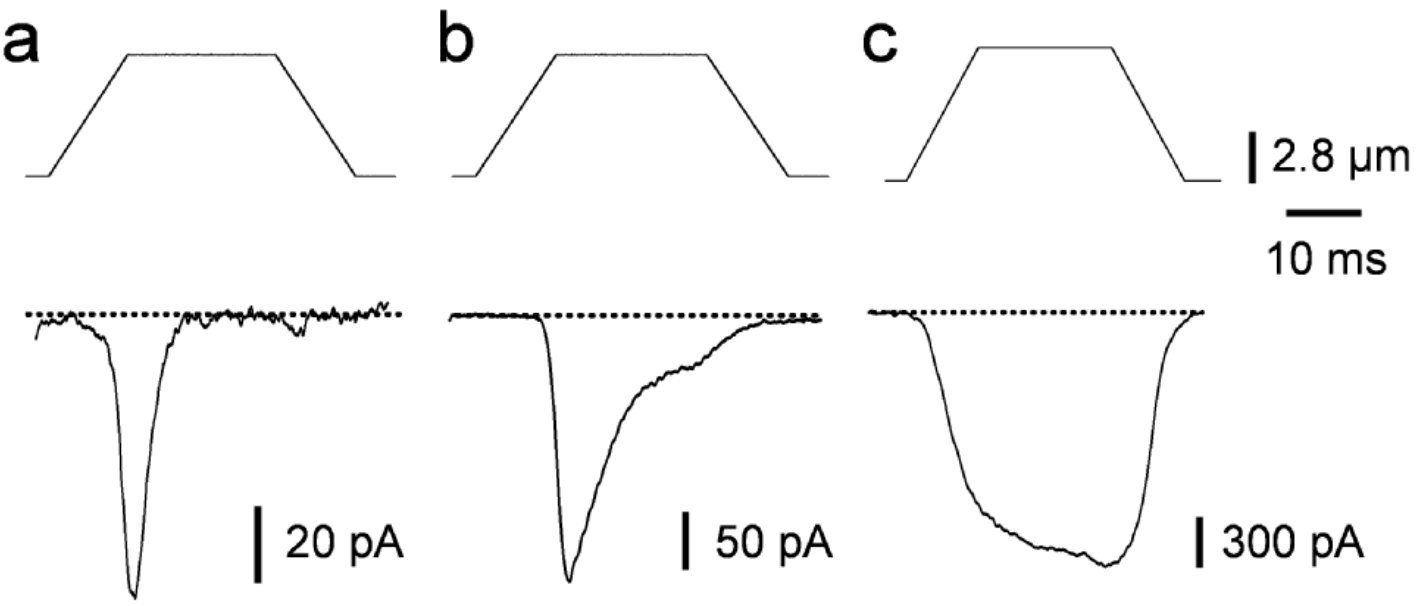

\footnotetext{
Figure 2. MS currents evoked by mechanical ramp stimuli in sensory neurons

MS currents showing rapid (a), intermediate (b) or no/slow (c) adaptations recorded in large, medium and small diameter sensory neurons, respectively. Mechanical ramp stimulations (top traces) were applied at a holding potential of $-60 \mathrm{mV}$; the probe velocity was $850 \mu \mathrm{m} . \mathrm{s}^{-1}$. (J. Hao, and P. Delmas, unpublished data).
}

Pharmacological studies of MS channels have been dominated by the use of unselective blockers such as metal cations. Not surprisingly, gadolinium $\left(\mathrm{Gd}^{3+}\right)$, a widely used blocker of various cationic conductances, blocked all MS currents in sensory neurons [3]. Amiloride, another non-selective drug that blocks many epithelial $\mathrm{Na}^{+}$channels and TRPP-like channels [17,50,51], inhibited most MS currents at relatively high concentrations [7]. These properties are shared by many mechano-gated cationic channels in other systems, including spider mechanoreceptor neurons, Xenopus oocytes and mammalian hair cells [52,53]. Recently, Drew et al. (2007) showed that a conopeptide analog termed NMB-1 (for noxious mechanosensation blocker 1) preferentially blocks SA MS currents in sensory neurons [54]. Indeed, NMB-1 has an approximate 30-fold selectivity for MS channels mediating SA currents over those carrying RA currents. Biotynylated NMB-1 principally binds to peripherincontaining DRG neurons, which are typically considered as nociceptors. Consistently, animals show reduced mechanically evoked behavioral responses to high intensity mechanical stimuli in the presence of NMB-1. Collectively, these data reinforce the view that SA and RA MS currents are expressed in functionally distinct sensory neuron populations and are carried by different molecular entities. 


\section{Candidate channels}

Genetic screens for mechanosensory mutants in invertebrates such as Drosophila and Caenorhabditis elegans have identified several molecular candidates that are supposed to mediate MS currents in mammals. These proteins belong to the degenerin/epithelial $\mathrm{Na}^{+}$channels (DEG/ENaC) and the TRP superfamilies.

\subsection{The DEG/ENaC superfamily}

The first evidence of the involvement of DEG/ENaC channels in mechanotransduction came from works on the nematode $C$. elegans. Mutant animals defective in mechanosensitive behaviors allowed the identification of several genes of the DEG/ENaC superfamily that are essential for mechanical transduction. Two DEG/ENaC ion channel subunits called MEC-4 and MEC-10 are required for sensing light touch [55-57]. These subunits form a mechanosensory complex, sensitivity of which can be modulated by extracellular tethers [57].

\section{Acid Sensing Ion Channels}

Acid Sensing Ion Channels (ASICs) belong to an $\mathrm{H}^{+}$-gated subgroup of the DEG/ENaC channel family of cation channels [58,59]. Four ASIC genes have been cloned and encode seven channel subunits. Although all ASIC channel subunits are expressed in the peripheral nervous system, only ASIC2a,b and ASIC3 are specifically expressed in mechanosensory neurons. They are expressed in dorsal root ganglia and transported from the cell bodies to the sensory nerve endings. Both channel subunits are also expressed in unmyelinated free nerve endings of the skin suggesting a role in the transduction of mechanonociceptive stimuli [60,61].

In contrast to MEC-4 and MEC-10 in C. elegans, ASIC channel subunits express well in recombinant systems. However, recombinant ASIC channels failed to demonstrate any mechanosensitivity [60,62]. Furthermore, the biophysical properties and pharmacology of these heterologously expressed ASIC channels differ from MS cation channels recorded in native sensory neurons [59], suggesting that ASIC subunits may not contribute to the pore-forming subunit of the mechanosensory apparatus. In line with this, no differences in current amplitude or kinetics of MS currents were seen in ASIC2/ASIC3 null mutant mice [4].

The role of ASIC channels has been also investigated in behavioral studies using mice with targeted deletion of ASIC channel genes. ASIC2 knock-out mice exhibit a decreased sensitivity of both RA and SA LTMs [61,63, see also 62]. By contrast, ASIC3 knock-out mice show increase in sensitivity of RA LTMs, no change in SA LTMs and reduced responses of myelinated HTMs to noxious stimuli. Although these data argue for the involvement of ASIC subunits in mechanotransduction, the definite demonstration that ASIC subunits carry MS currents in mammalian sensory neurons awaits further experiments.

\section{$\underline{\text { Stomatin }}$}

In C. elegans, MEC-2 encodes an integral membrane protein with a stomatin homology domain involved in touch receptor function. MEC-2 exhibits a central sequence of 247 amino acids that possess $64 \%$ homology with the mammalian protein stomatin [64]. 
The use of mutant mice lacking stomatin like-protein $3\left(\mathrm{Slp}^{-/}\right)$provided evidence to suggest that SLP3 is an important determinant of skin mechanoreceptor functions [65]. About $36 \%$ of sensory neurons recorded in vitro show no responses to mechanical stimuli in $\operatorname{Slp} 3^{-/}$mice, compared with less than $5 \%$ in wild-type sensory neurons. Because the proportion of cells that normally display RA and SA MS currents decreased conjointly, one may hypothesized that SLP3 is necessary for both types of underlying MS channels. At the behavioral level, the loss of SPL3 impairs tactile discrimination capability and touch-evoked pain following neuropathic injury [65]. Therefore SLP3 appears as an essential element of the mechanosensory apparatus in mammalian mechanoreceptors. Although its precise function is still unknown, SPL3 may be envisioned as a putative linker between MS channel subunits and the underlying microtubules, as proposed for its C. elegans homologue MEC-2 [64,66].

\subsection{The TRP superfamily}

Some of the most promising candidates for mechanically activated channels are members of the TRP superfamily, which is subdivided into 7 subfamilies [67,68]. These channels play critical roles in sensory physiology, including requirements for thermosensation, olfaction, hearing and osmoregulation.

\section{$\underline{\text { TRPV channels }}$}

TRP channels of the vanilloid receptor (TRPV) group are best known for sensing heat and mediating neurogenic inflammation, but some have also been implicated in mechanosensation. TRPV1, which is activated by capsaicin, heat, acid and various lipids, is also required for normal stretch-evoked reflexes in the bladder [69] and for osmosensation in circumventricular neurons [70]. TRPV1 is strongly expressed in a subset of mammalian sensory neurons. However, it cannot directly sense and respond to mechanical stimuli [71] and Trpv1-null mutant mice exhibit normal acute mechanical sensitivity and mechanical hyperalgesic responses following tissue inflammation [72,73].

Some evidence implicated TRPV2 in aortic myocyte responses to membrane stretch and hypotonic stimulation [74] and in constriction of blood vessels under increasing pressure [75]. TRPV2 is preferentially expressed in large-diameter somatosensory neurons but its role in mechanotransduction remains to be tested [76].

TRPV4 has been proposed to act as an osmosensor because, in addition to warm temperature and acidic $\mathrm{pH}$, it is activated by cell-swelling through an indirect mechanism requiring fatty acid metabolites [77,78]. In that sense, TRPV4 cannot be considered as a real mechanosensor and there must be an upstream element to fulfil this function. TRPV4 is a crucial determinant in shaping the response of nociceptive neurons to osmotic stress [35,79]. Disrupting Trpv4 expression in mice has only modest effects on acute mechanosensory thresholds, but strongly reduces sensitivity to noxious mechanical stimuli $[80,81]$. In addition, TRPV4 has been implicated in mechanical hypersensitivity during inflammation [35,82].

\section{$\underline{\text { TRPC1 channels }}$}

Known as a store- and receptor-operated channel, the canonical TRP channel TRPC1 has been recently proposed to form the stretch-activated cation channel constitutively expressed in Xenopus oocytes [83-85]. TRPC1 antisense reduces the endogenous stretch-activated current in oocytes, 
whereas overexpression of TRPC1 increases the current [84]. Moreover, TRPC1 expression in CHO$\mathrm{K} 1$ cells results in a 5-fold increase in MS cation current density [84]. Against the presumed role of TRPC1 in mechanotransduction, however, is the observation that this channel is widely expressed in mammalian cells, most being devoid of mechanosensory functions. Perhaps, the mechanosensitive signaling properties of TRPC1 rely on its interaction with other MS TRP subunits. Evidence has appeared to suggest that TRPC1 can interact with the putative MS TRPP2, a channel involved in mechanical detection of laminar fluid flow in renal epithelial cells [86-88]. Still to be tested is whether TRPC1/TRPP2 heteromers form functional channels that sense mechanical stimuli.

\section{TRPA1 channels}

NompC, a member of the TRPN cation channel subfamily in Drosophila, together with its homologues in $C$. elegans and some vertebrates, have been consistently implicated to play critical roles in mechanotransduction [89-94]. A unique feature of these TRPN-related channels is their large Nterminal domains harboring numerous ankyrin repeats. This prompted suggestion that these $\mathrm{N}$-terminal domains may serve as tension transmission structures to the pore forming region.

TRPN channels are not present in the genome of reptiles, birds and mammals [95]. The only mammalian TRP subunit with an extended domain of ankryin repeats is TRPA1. This subunit was suggested to form the main mechanotransducing channel of the inner ear [96-98], but this proposal was not corroborated by knocking out strategies, since $\operatorname{Trpal}^{-1-}$ mice showed normal auditory responses and hair cell transduction currents [99,100]. Recently, the $C$. elegans ortholog of mouse TRPA1 has been shown to be expressed in mechanosensory neurons, where it contributes to neural responses to touch [101]. In addition, mechanical pressure can activate $C$. elegans TRPA1 heterologously expressed in mammalian cells. These data demonstrate for the first time that $C$. elegans TRPA1 encodes an ion channel that can be activated in response to mechanical pressure.

The expression of TRPA1 in small diameter neurons of dorsal root and trigeminal ganglia in mammals led to the suggestion of its possible implication in mechanical pain sensation $[97,102,103]$. Consistent with its expression pattern in sensory neurons, mice lacking TRPA1 are deficient in the detection of acute high-threshold mechanical stimuli applied to the extremities [100]. However, contrary to these findings, the Julius group did not report deficit in responses to noxious mechanical stimuli in Trpal ${ }^{-1-}$ mice [99]. Kwan et al. (2006) went further on to demonstrate a role of TRPA1 in mechanical hyperalgesia, by showing that mechanical pain threshold after bradykinin-induced inflammation is significantly higher in $\operatorname{Trpal}^{-/-}$mice compared to wild-type [100]. Taken together, these data provide substantial evidence suggesting that TRPA1 mediates responses to high-threshold mechanical stimuli in nociceptive neurons. However, further investigations are clearly needed to determine whether TRPA1 is a real mechanotransducing channel and to clarify the existing discrepancies regarding its role in mammalian mechanosensation.

\section{Conclusion}

It is well known that mechanonociceptors and low threshold mechanoreceptors in vivo have different sensitivity and stimulus specificity. Although this may be explained in part by the geometry of the specialized terminal structures and interaction with support cells, this functional specificity 
provides strong hints that distinct transduction mechanisms underlay touch and pressure-evoked pain. However, unlike with other sensory transduction processes, there has been a lack of in vitro models to address these questions at the cellular and molecular levels. The development of a new technique that allows to monitor membrane tension changes while recording mechanotransduction currents was proved very useful in addressing many of these unresolved issues. It became clearly apparent that sensory neurons express MS currents with different mechanical threshold, adapting kinetics and pharmacology, raising the possibility that more than one mechanotransduction channel may be operating in subspecialized mechanoreceptive neurons.

What then are the candidate channels? Based on genetic studies in mammalian and non-mammalian species, members of the $\mathrm{DEG} / \mathrm{ENaC}$ and TRP channel superfamilies are currently the more attractive candidates. Many fulfil some basic criteria for mechanosensitivity but most remain potential candidates. Even with candidate in hands, further studies will be required to fully elucidate their roles and the molecular mechanisms of mechanosensation.

\section{Acknowledgements}

This work was supported by the CNRS, the University of Méditerranée, Foundation Schumberger, Agence Nationale pour la Recherche, and the French Ministry of Education and Research. M.R. is a recipient of the Fondation pour la Recherche Médicale (FRM).

\section{References and Notes}

1. Olausson, H.; Lamarre, Y.; Backlund, H.; Morin, C.; Wallin, B.G.; Starck, G.; Ekholm, S.; Strigo, I.; Worsley, K.; Vallbo, A.B.; Bushnell, M.C. Unmyelinated tactile afferents signal touch and project to insular cortex. Nat. Neurosci. 2002, 5, 900-904.

2. McCarter, G.C.; Reichling, D.B.; Levine, J.D. Mechanical transduction by rat dorsal root ganglion neurons in vitro. Neurosci. Lett. 1999, 273, 179-182.

3 Drew, L.J.; Wood, J.N.; Cesare, P. Distinct mechanosensitive properties of capsaicin-sensitive and -insensitive sensory neurons. J. Neurosci. 2002, 22, 228.

4 Drew, L.J.; Rohrer, D.K.; Price, M.P.; Blaver, K.E.; Cockayne, D.A.; Cesare, P.; Wood, J.N. Acid-sensing ion channels ASIC2 and ASIC3 do not contribute to mechanically activated currents in mammalian sensory neurons. J. Physiol. 2004, 556, 691-710.

$5 \mathrm{Hu}$, J.; Lewin, G.R. Mechanosensitive currents in the neurites of cultured mouse sensory neurons. J. Physiol. 2006, 577, 815-828.

6 McCarter, G.C.; Levine, J.D. Ionic basis of a mechanotransduction current in adult rat dorsal root ganglion neurons. Mol. Pain 2006, 2, 28.

7 Coste, B.; Crest, M.; Delmas, P. Pharmacological dissection and distribution of NaN/Nav1.9, Ttype $\mathrm{Ca}^{2+}$ currents, and mechanically activated cation currents in different populations of DRG neurons. J. Gen. Physiol. 2007, 129, 57-77.

8 Hamill, O.P. Twenty odd years of stretch-sensitive channels. Pflügers Arch. 2006, 453, 333-351.

9 Cho, H.; Shi, J.; Shin, C.Y.; Lee, S.Y.; Oh, U. Mechanosensitive ion channels in cultured sensory neurons of neonatal rats. J. Neurosci. 2002, 22, 1238-1247. 
10 Gottlieb, P.A.; Suchyna, T.M.; Ostrow, L.W.; Sachs, F. Mechanosensitive ion channels as drug targets. Curr. Drug Targets CNS Neurol. Disord. 2004, 3, 287-295.

11 Suchyna, T.M.; Tape, S.E.; Koeppe, R.E.; Andersen, O.S.; Sachs, F.; Gottlieb, P.A. Bilayerdependent inhibition of mechanosensitive channels by neuroactive peptide enantiomers. Nature 2004, 430, 235-240.

12 Yuan, X.; Luo, S.; Lin, Z.; Wu, Y. Cyclic stretch translocates the alpha2-subunit of the Na pump to plasma membrane in skeletal muscle cells in vitro. Biochem. Biophys. Res. Commun. 2006, 348, 750-757.

13 Guharay, F.; Sachs, F. Stretch-activated single ion channel currents in tissue-cultured embryonic chick skeletal muscle. J. Physiol. 1984, 352, 685-701.

14 Takahashi, A.; Gotoh, H. Mechanosensitive whole-cell currents in cultured rat somatosensory neurons. Brain Res. 2000, 869, 225-230.

15 Praetorius, H.A.; Spring, K.R. Bending the MDCK cell primary cilium increases intracellular calcium. J. Membr. Biol. 2001, 184, 71-79.

16 Giamarchi, A.; Delmas, P. Activation mechanisms and functional roles of TRPP2 cation channels. In TRP ion channel function in sensory transduction and cellular signaling cascades; Boca Raton, F.L. (Ed.); Frontiers in Neuroscience, New York, NY, 2006; pp. 189-202.

17 Giamarchi, A.; Padilla, F.; Coste, B.; Raoux, M.; Crest, M.; Honoré, E.; Delmas, P. The versatile nature of the calcium-permeable cation channel TRPP2. Embo Rep. 2006, 7, 787-793.

18 Davies, P.F.; Mundel, T.; Barbee, K.A. A mechanism for heterogeneous endothelial responses to flow in vivo and in vitro. J. Biomech. 1995, 28, 1553-1560.

19 Tulis, D.A.; Unthank, J.L.; Prewitt, R.L. Flow-induced arterial remodeling in rat mesenteric vasculature. Am. J. Physiol. 1998, 274, 874-882.

20 Spungin, B.; Silberberg, A. Stimulation of mucus secretion, ciliary activity, and transport in frog palate epithelium. Am. J. Physiol. 1984, 247, 299-308.

21 Andrade, Y.N.; Fernandes, J.; Vazquez, E.; Fernandez-Fernandez, J.M.; Arniges, M.; Sanchez, T.M.; Villalon, M.; Valverde, M.A. TRPV4 channel is involved in the coupling of fluid viscosity changes to epithelial ciliary activity. J. Cell. Biol. 2005, 168, 869-874.

22 Winters, S.L.; Davis, C.W.; Boucher, R.C. Mechanosensitivity of mouse tracheal ciliary beat frequency: roles for $\mathrm{Ca}^{2+}$, purinergic signaling, tonicity, and viscosity. Am. J. Physiol. Lung. Cell. Mol. Physiol. 2007, 292, 614-624.

23 Cunningham, J.T.; Wachtel, R.E.; Abboud, F.M. Mechanosensitive currents in putative aortic baroreceptor neurons in vitro. J. Neurophysiol. 1995, 73, 2094-2098.

24 Martinac, B. Mechanosensitive ion channels: molecules of mechanotransduction. J. Cell. Sci. 2004, 117, 2449-2460.

25 O'Neil, R.G.; Heller, S. The mechanosensitive nature of TRPV channels. Pflügers Arch. 2005, 451, 193-203.

26 Lin, S.Y.; Corey, D.P. TRP channels in mechanosensation. Curr. Opin. Neurobiol. 2005, 15, 350357.

27 Nilius, B.; Eggermont, J.; Voets, T.; Droogmans, G. Volume-activated $\mathrm{Cl}^{-}$channels. Gen. Pharmacol. 1996, 27, 1131-1140. 
28 Strange, K.; Emma, F.; Jackson, P.S. Cellular and molecular physiology of volume-sensitive anion channels. Am. J. Physiol. 1996, 270, 711-730.

29 Okada, Y. Volume expansion-sensing outward-rectifier $\mathrm{Cl}^{-}$channel: fresh start to the molecular identity and volume sensor. Am. J. Physiol. 1997, 273, 755-789.

30 Nilius, B.; Voets, T.; Prenen, J.; Barth, H.; Aktories, K.; Kaibuchi, K.; Droogmans, G.; Eggermont, J. Role of Rho and Rho kinase in the activation of volume-regulated anion channels in bovine endothelial cells. J. Physiol. 1999, 516, 67-74.

31 Wiese, K.G. Electrolyte concentration, real and osmotic pressure in abscesses. Zentralbl. Chir. 1994, 119, 54-59.

32 Wiese, K.G.; Merten, H.A.; Wiltfang, J.; Luhr, H.G. Clinical studies on the pathophysiology of odontogenic abscesses. Mund Kiefer Gesichtschir. 1999, 3, 242-246.

33 Tsai, T.F.; Maibach, H.I. How irritant is water? An overview. Contact Dermatitis 1999, 41, 311 314.

34 Misery, L.; Meyronet, D.; Pichon, M.; Brutin, J.L.; Pestre, P.; Cambazard, F. Aquadynia: a role for VIP? Ann. Dermatol. Venereol. 2003, 130, 195-198.

35 Alessandri-Haber, N.; Joseph, E.; Dina, O.A.; Liedtke, W.; Levine, J.D. TRPV4 mediates painrelated behavior induced by mild hypertonic stimuli in the presence of inflammatory mediator. Pain 2005, 118, 70-79.

36 Boudreault, F.; Grygorczyk, R. Cell swelling-induced ATP release and gadolinium-sensitive channels. Am. J. Physiol. Cell. Physiol. 2002, 282, 219-226.

37 Kimura, C.; Oike, M.; Ohnaka, K.; Nose, Y.; Ito, Y. Constitutive nitric oxide production in bovine aortic and brain microvascular endothelial cells: a comparative study. J. Physiol. 2004, 554, 721730.

38 Von Weikersthal, S.F.; Barrand, M.A.; Hladky, S.B. Functional and molecular characterization of a volume-sensitive chloride current in rat brain endothelial cells. J. Physiol. 1999, 516, 75-84.

39 Strotmann, R.; Harteneck, C.; Nunnenmacher, K.; Schultz, G.; Plant, T.D. OTRPC4, a nonselective cation channel that confers sensitivity to extracellular osmolarity. Nat. Cell. Biol. 2000, 2, 695-702.

40 Srinivas, S.P.; Maertens, C.; Goon, L.H.; Goon, L.; Satpathy, M.; Yue, B.Y.; Droogman, G.; Nilius, B. Cell volume response to hyposmotic shock and elevated cAMP in bovine trabecular meshwork cells. Exp. Eye Res. 2003, 78, 15-26.

41 Liu, X.; Bandyopadhyay, B.; Nakamoto, T.; Singh, B.; Liedtke, W.; Melvin, J.E.; Ambudkar, I. A role for AQP5 in activation of TRPV4 by hypotonicity: concerted involvement of AQP5 and TRPV4 in regulation of cell volume recovery. J. Biol. Chem. 2006, 281, 15485-1595.

42 Raoux, M.; Colomban, C.; Delmas, P.; Crest, M. The amine-containing cutaneous irritant heptylamine inhibits the volume-regulated anion channel and mobilizes intracellular calcium in normal human epidermal keratinocytes. Mol. Pharmacol. 2007, 71, 1685-1694.

43 Sheetz, M.P.; Singer, S.J. Biological membranes as bilayer couples. A molecular mechanism of drug-erythrocyte interactions. Proc. Natl Acad. Sci. USA 1974, 71, 4457-4461.

44 Sheetz, M.P.; Singer, S.J. Equilibrium and kinetic effects of drugs on the shapes of human erythrocytes. J. Cell. Biol. 1976; 70, 247-251. 
45 Martinac, B.; Adler, J.; Kung, C. Mechanosensitive ion channels of E. coli activated by amphipaths. Nature 1990, 348, 261-263.

46 Sokabe, M.; Hasegawa, N.; Yamamori, K. Blockers and activators for stretch-activated ion channels of chick skeletal muscle. Ann. NY Acad. Sci. 1993, 707, 417-420.

47 Patel, A.J.; Honore, E.; Maingret, F.; Lesage, F.; Fink, M.; Duprat, F.; Lazdunski, M. A mammalian two pore domain mechano-gated S-like $\mathrm{K}^{+}$channel. Embo J. 1998, 17, 4283-4290.

48 Maingret, F.; Fosset, M.; Lesage, F.; Lazdunski, M.; Honoré, E. TRAAK is a mammalian neuronal mechano-gated $\mathrm{K}^{+}$channel. J. Biol. Chem. 1999, 274, 1381-1387.

49 Lewin, G.R.; Moshourab, R. Mechanosensation and pain. J. Neurobiol. 2004, 61, 30-44.

50 Kleyman, T.R.; Cragoe, E.J. Amiloride and its analogs as tools in the study of ion transport. $J$. Memb. Biol. 1988, 105, 1-21.

51 Delmas, P.; Nauli, S.M.; Li, X.; Coste, B.; Osorio, N.; Crest, M.; Brown, D.A.; Zhou, J. Gating of the polycystin ion channel signaling complex in neurons and kidney cells. Faseb J. 2004, 18, 740742.

52 Hamill, O.P.; McBride, D.W. The pharmacology of mechanogated membrane ion channels. Pharmacol. Rev. 1996, 48, 231-252.

53 Höger, U.; Torkkeli, P.H.; Seyfarth, E.A.; French, A.S. Ionic selectivity of mechanically activated channels in spider mechanoreceptor neurons. J. Neurophysiol. 1997, 78, 2079-2085.

54 Drew, L.J.; Rugiero, F.; Cesare, P.; Gale, J.E.; Abrahamsen, B.; Bowden, S.; Heinzmann, S.; Robinson, M.; Brust, A.; Colless, B.; Lewis, R.J.; Wood, J.N. High-threshold mechanosensitive ion channels blocked by a novel conopeptide mediate pressure-evoked pain. PLOS ONE 2007, 2, 515.

55 Tavernarakis, N.; Driscoll, M. Molecular modeling of mechanotransduction in the nematode Caenorhabditis elegans. Annu. Rev. Physiol. 1997, 59, 659-689.

56 Gillespie, P.G.; Walker, R.G. Molecular basis of mechanosensory transduction. Nature 2001, 413, 194-202.

57 Bounoutas, A.; Chalfie, M. Touch sensitivity in Caenorhabditis elegans. Pflügers Arch. 2007, 454, 691-702.

58 Waldmann, R.; Lazdunski, M. $\mathrm{H}^{+}$-gated cation channels: neuronal acid sensors in the NaC/DEG family of ion channels. Curr. Opin. Neurobiol. 1998, 8, 418-424.

59 Lingueglia, E. Acid-sensing ion channels in sensory perception. J. Biol. Chem. 2007, 282, 1732517329.

60 García-Añoveros, J.; Samad, T.A.; Zuvela-Jelaska, L.; Woolf, C.J.; Corey, D.P. Transport and localization of the $\mathrm{DEG} / \mathrm{ENaC}$ ion channel $\mathrm{BNaClalpha}$ to peripheral mechanosensory terminals of dorsal root ganglia neurons. J. Neurosci. 2001, 21, 2678-2686.

61 Price, M.P.; McIlwrath, S.L.; Xie, J.; Cheng, C.; Qiao, J.; Tarr, D.E.; Sluka, K.A.; Brennan, T.J.; Lewin, G.R.; Welsh, M.J. The DRASIC cation channel contributes to the detection of cutaneous touch and acid stimuli in mice. Neuron 2001, 32, 1071-1083.

62 Roza, C.; Puel, J.L.; Kress, M.; Baron, A.; Diochot, S.; Lazdunski, M.; Waldmann, R. Knockout of the ASIC2 channel in mice does not impair cutaneous mechanosensation, visceral mechanonociception and hearing. J. Physiol. 2004, 558, 659-669. 
63 Price, M.P.; Lewin, G.R.; McIlwrath, S.L.; Cheng, C.; Xie, J.; Heppenstall, P.A.; Stucky, C.L.; Mannsfeldt, A.G.; Brennan, T.J.; Drummond, H.A.; Qiao, J.; Benson, C.J.; Tarr, D.E.; Hrstka, R.F.; Yang, B.; Williamson, R.A.; Welsh, M.J. The mammalian sodium channel BNC1 is required for normal touch sensation. Nature 2000, 407, 1007-1011.

64 Huang, M.; Gu, G.; Ferguson, E.L.; Chalfie, M.A. Stomatin-like protein necessary for mechanosensation in C. elegans. Nature 1995, 378, 292-295.

65 Wetzel, C.; Hu, J.; Riethmacher, D.; Benckendorff, A.; Harder, L.; Eilers, A.; Moshourab, R.; Kozlenkov, A.; Labuz, D.; Caspani, O.; Erdmann, B.; Machelska, H.; Heppenstall, P.A.; Lewin, G.R. A stomatin-domain protein essential for touch sensation in the mouse. Nature 2007, 445, 206-209.

66 Stewart, G.W. Stomatin. Int. J. Biochem. Cell. Biol. 1997, 29, 271-274.

67 Nilius, B.; Voets, T. TRP channels: a TR(I)P through a world of multifunctional cation channels. Pflügers Arch. 2005, 451, 1-10.

68 Nilius, B.; Owsianik, G.; Voets, T.; Peters, J.A. Transient receptor potential cation channels in disease. Physiol. Rev. 2007, 87, 165-217.

69 Birder, L.A.; Nakamura, Y.; Kiss, S.; Nealen, M.L.; Barrick, S.; Kanai, A.J.; Wang, E.; Ruiz, G.; De Groat, W.C.; Apodaca, G.; Watkins, S.; Caterina, M.J. Altered urinary bladder function in mice lacking the vanilloid receptor TRPV1. Nature Neurosci. 2002, 5, 856-860.

70 Sharif Naeini, R.; Witty, M.F.; Seguela, P.; Bourque, C.W. An N-terminal variant of Trpv1 channel is required for osmosensory transduction. Nature Neurosci. 2006, 9, 93-98.

71 Gunthorpe, M.J.; Benham, C.D.; Randall, A.; Davis, J.B. The diversity in the vanilloid (TRPV) receptor family of ion channels. Trends Pharmacol. Sci. 2002, 23, 183-191.

72 Caterina, M.J.; Leffler, A.; Malmberg, A.B.; Martin, W.J.; Trafton, J.; Petersen-Zeitz, K.R.; Koltzenburg, M.; Basbaum, A.I.; Julius, D. Impaired nociception and pain sensation in mice lacking the capsaicin receptor. Science 2000, 288, 306-313.

73 Davis, J.B.; Gray, J.; Gunthorpe, M.J.; Hatcher, J.P.; Davey, P.T.; Overend, P.; Harries, M.H.; Latcham, J.; Clapham, C.; Atkinson, K.; Hughes, S.A.; Rance, K.; Grau, E.; Harper, A.J.; Pugh, P.L.; Rogers, D.C.; Bingham, S.; Randall, A.; Sheardown, S.A. Vanilloid receptor-1 is essential for inflammatory thermal hyperalgesia. Nature 2000, 405, 183-187.

74 Muraki, K.; Iwata, Y.; Katanosaka, Y.; Ito, T.; Ohya, S.; Shigekawa, M.; Imaizumi, Y. TRPV2 is a component of osmotically sensitive cation channels in murine aortic myocytes. Circ. Res. 2003, 93, 829-838.

75 Davis, M.J.; Hill, M.A. Signaling mechanisms underlying the vascular myogenic response. Physiol. Rev. 1999, 79, 387-423.

76 Caterina, M.J.; Julius, D. The vanilloid receptor: a molecular gateway to the pain pathway. Annu. Rev. Neurosci. 2001, 24, 487-517.

77 Vriens, J.; Watanabe, H.; Janssens, A.; Droogmans, G.; Voets, T.; Nilius, B. Cell swelling, heat, and chemical agonists use distinct pathways for the activation of the cation channel TRPV4. Proc. Natl Acad. Sci. USA 2004, 101, 396-401.

78 Liedtke, W. TRPV4 as osmosensor: a transgenic approach. Pflügers Arch. 2005, 451, 176-180. 
79 Liedtke, W.; Choe, Y.; Martí-Renom, M.A.; Bell, A.M.; Denis, C.S.; Sali, A.; Hudspeth, A.J.; Friedman, J.M.; Heller, S. Vanilloid receptor-related osmotically activated channel (VR-OAC), a candidate vertebrate osmoreceptor. Cell 2000, 103, 525-535.

80 Liedtke, W.; Friedman, J.M. Abnormal osmotic regulation in trpv4 ${ }^{-/}$mice. Proc. Natl Acad. Sci. USA 2003, 100, 13698-13703.

81 Suzuki, M.; Mizuno, A.; Kodaira, K.; Imai, M. Impaired pressure sensation in mice lacking TRPV4. J. Biol. Chem. 2003, 278, 22664-22668.

82 Alessandri-Haber, N.; Dina, O.A.; Yeh, J.J.; Parada, C.A.; Reichling, D.B.; Levine, J.D. Transient receptor potential vanilloid 4 is essential in chemotherapy-induced neuropathic pain in the rat. $J$. Neurosci. 2004, 24, 4444-4452.

83 Parekh, A.B.; Putney, J.W. Store-operated calcium channels. Physiol. Rev. 2005, 85, 757-810.

84 Maroto, R.; Raso, A.; Wood, T.G.; Kurosky, A.; Martinac, B.; Hamill, O.P. TRPC1 forms the stretch-activated cation channel in vertebrate cells. Nat. Cell. Biol. 2005, 7, 179-185.

85 Hamill, O.P.; Maroto, R. TRPCs as MS channels. Curr. Top. Membr. 2007, 59 (in press).

86 Tsiokas, L.; Arnould, T.; Zhu, C.; Kim, E.; Walz, G.; Sukhatme, V.P. Specific association of the gene product of PKD2 with the TRPC1 channel. Proc. Natl Acad. Sci. USA 1999, 96, 3934-3939.

87 Delmas, P. Polycystins: from mechanosensation to gene regulation. Cell 2004, 118, 145-148.

88 Delmas, P. Assembly and gating of TRPC channels in signalling microdomains. In Mammalian TRP Channels as Molecular Targets; John Wiley \& Sons, Ltd. Novartis Found. Symp., 2004, 258, 75-97.

89 Eberl, D.F.; Hardy, R.W.; Kernan, M.J. Genetically similar transduction mechanisms for touch and hearing in Drosophila. J. Neurosci. 2000, 20, 5981-5988.

90 Walker, R.G.; Willingham, A.T.; Zuker, C.S. A Drosophila mechanosensory transduction channel. Science 2000, 287, 2229-2234.

91 Sidi, S.; Friedrich, R.W.; Nicolson, T. NompC TRP channel required for vertebrate sensory hair cell mechanotransduction. Science 2003, 301, 96-99.

92 Shin, J.B.; Adams, D.; Paukert, M.; Siba, M.; Sidi, S.; Levin, M.; Gillespie, P.G.; Gründer, S. Xenopus TRPN1 (NOMPC) localizes to microtubule-based cilia in epithelial cells, including inner-ear hair cells. Proc. Natl Acad. Sci. USA 2005, 102, 12572-12577.

93 Gopfert, M.C.; Albert, J.T.; Nadrowski, B.; Kamikouchi, A. Specification of auditory sensitivity by Drosophila TRP channels. Nature Neurosci. 2006, 9, 999-1000.

94 Li, W.; Feng, Z.; Sternberg, P.W.; Xu, X.Z. A C. elegans stretch receptor neuron revealed by a mechanosensitive TRP channel homologue. Nature 2006, 440, 684-687.

95 Corey, D.P. What is the hair cell transduction channel? J. Physiol. 2006, 576, 23-28.

96 Corey, D.P.; García-Añoveros, J.; Holt, J.R.; Kwan, K.Y.; Lin, S.Y.; Vollrath, M.A.; Amalfitano, A.; Cheung, E.L.; Derfler, B.H.; Duggan, A.; Geleoc, G.S.; Gray, P.A.; Hoffman, M.P.; Rehm, H.L.; Tamasauskas, D.; Zhang, D.S. TRPA1 is a candidate for the mechanosensitive transduction channel of vertebrate hair cells. Nature 2004, 432, 723-730

97 Nagata, K.; Duggan, A.; Kumar, G.; García-Añoveros, J. Nociceptor and hair cell transducer properties of TRPA1, a channel for pain and hearing. J. Neurosci. 2005, 25, 4052-4061. 
98 Vollrath, M.A.; Kwan, K.Y.; Corey, D.P. The micromachinery of mechanotransduction in hair cells. Annu. Rev. Neurosci. 2007, 30, 339-365.

99 Bautista, D.M.; Jordt, S.E.; Nikai, T.; Tsuruda, P.R.; Read, A.J.; Poblete, J.; Yamoah, E.N.; Basbaum, A.I.; Julius; D. TRPA1 mediates the inflammatory actions of environmental irritants and proalgesic agents. Cell 2006, 124, 1269-1282.

100 Kwan, K.Y.; Allchorne, A.J.; Vollrath, M.A.; Christensen, A.P.; Zhang, D.S.; Woolf, C.J.; Corey, D.P. TRPA1 contributes to cold, mechanical, and chemical nociception but is not essential for hair-cell transduction. Neuron 2006, 50, 277-289.

101 Kindt, K.S.; Viswanath, V.; Macpherson, L.; Quast, K.; Hu, H.; Patapoutian, A.; Schafer, W.R. Caenorhabditis elegans TRPA-1 functions in mechanosensation. Nat. Neurosci. 2007, 10, 568577.

102 Story, G.M.; Peier, A.M.; Reeve, A.J.; Eid, S.R.; Mosbacher, J.; Hricik, T.R.; Earley, T.J.; Hergarden, A.C.; Andersson, D.A.; Hwang, S.W.; McIntyre, P.; Jegla, T.; Bevan, S.; Patapoutian, A. ANKTM1, a TRP-like channel expressed in nociceptive neurons, is activated by cold temperatures. Cell 2003, 112, 819-829.

103 Bautista, D.M.; Movahed, P.; Hinman, A.; Axelsson, H.E.; Sterner, O.; Högestätt, E.D.; Julius, D.; Jordt, S.E.; Zygmunt, P.M. Pungent products from garlic activate the sensory ion channel TRPA1. Proc. Natl Acad. Sci. USA 2005, 102, 12248-12252.

(C) 2007 by MDPI (http://www.mdpi.org). Reproduction is permitted for noncommercial purposes. 